Leech, who affirmed that the sea-cow was really a sea lion, is mentioned in Brooke's "History of St. Helena" (1824 ed., p. 5I), as one "who by his unwearied pursuits in historical research, and his surprisingly retentive memory had acquired a great degree of general information".

There is another very important reference in Dr. Walter Henry's "Events of a Military Life" (2nd ed., Pickering, London, 1843, vol. 2, pp. 66 and 67), which is as follows :

"We had sea-cows at St. Helena, the Trichechus Dugong, but they were not common. When shooting near Buttermilk Point with another officer one calm evening, we stumbled on one lying on a low rock close to the water's edge, and a hideous ugly brute it was, shaped like a large calf, with bright green eyes as big as saucers. We only caught a glimpse of it for a few seconds, for as soon as it noticed us, it jumped into the sea, in the most awkward and sprawling manner."

Dr. Henry, whose book is well known to Napoleonic students, was an alert and accurate observer of current events, who later reached high rank in the Army Medical Service and died in 1860. His observations were made between 1817 and 1821 ; probably in 1819 .

It may be a convenience to students if I recapitulate the references to be found to sea-cows in the Public Records of Jamestown :

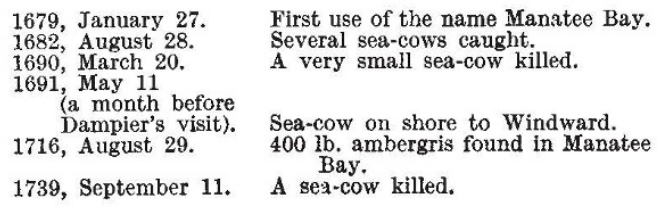

Burnham's sea-cow of 1810 referred to by Lydekker and Mortensen, I am unable to trace as recorded in the Public Records; but the latter quotes Janisch's confirmation of it to be found in "Scraps from Records" (Government Printer, Jamestown, 1880, to accompany the St. Helena Almanack of that year).

The Castle,

St. Helena.

April 18.

\section{A Case of 50 per cent Crossing-over in the Male Drosophila}

Wiтн the view of synthesising a double recessive black-vestigial stock of Drosophila melanogaster, Dr. G. Eloff ${ }^{1}$ made a eross of black and vestigial, both of which are contained in the second chromosome. The $F_{2}$ generation, to his surprise, contained many $b v g$ flies. To solve the question, the $F_{1}$ males were mated with double recessive females $(b v g)$, when an independent segregation of black and vestigial was found. $\mathrm{He}$ applied the fact to the $F_{2}$ data to calculate the crossing-over value between $b$ and $v g$ in the female, and estimated it to be 17.8 per cent. The value is close to the standard value of $17 \cdot 0$ per cent (18.5 per cent, according to the recent census). For his 50 per cent crossing-over in the male, he writes : "Some other explanation (for example, of chromosomal mutation) must be offered".

In my opinion, Dr. Eloff used by mistake the other mutant, ebony for example, that appears in another chromosome. If so, the black body colour should be inherited independently with vestigial, and it would be quite the natural thing that there should be a $\mathbf{5} 0$ per cent crossing-over in the male. According to my understanding, his $F_{2}$ data seem to be nothing but the result of an independent segregation, although deviation was considerable.

$$
\begin{aligned}
& \text { Furitsu Koto-Gakko, } \\
& \text { Biological Institute, } \\
& \text { Meguro, Tokyo. } \\
& \text { March } 6 . \\
& \text { ' G. Eloff, NATURE, 137, } 151 \text { (1936). }
\end{aligned}
$$

DaIgoro MoRIWaKI.

SrNCE the appearance of my letter in NATURE of January 25, Prof. Tammes of Groningen has written to me as follows : "Gottschewski (of Berlin-Dahlem) is of opinion that the 'black' which you used was probably not the normal black but the so-called "black Kreidel Holland' which is the same as sooty . . ."

The stock which I received from Groningen was only labelled 'black'. But it probably was a 'sooty' culture from stocks used by Dr. van Herwerden (and her student Kreidel), who got their cultures from America and Berlin-Dahlem. For some reason which is not clear to me at present, this 'sooty' stock was either labelled "black Kreidel Holland" or "black".

In order to make sure that it was the 'black' culture which was responsible for the independent segregation obtained, I this time made use of a vestigial stock from Berlin-Dahlem. The class representations of two series of repulsion back. crosses, the $F_{2}$ of which I have just finished counting, were as follows:

$F_{1}$ ơ back-crosses : $204 \mathrm{BV}, 235 \mathrm{bV}, 194 \mathrm{Bv}, 171 \mathrm{bv}$

$$
\frac{B V+b v}{B V+b V+B v+b v}=\text { approx. } 46 \cdot 6 \text { per cent. }
$$

$F_{1}$ o back-crosses : $701 \mathrm{BV}, 839 \mathrm{bV}, 670 \mathrm{Bv}, 698 \mathrm{bv}$

$$
\frac{B V+b v}{B V+b V+B v+b v}=\text { approx. } 48 \cdot 1 \text { per cent. }
$$

As the data refer to repulsion crosses only, the unequal representation of the classes may be ex. plained by (1) difficult separation of $b V$ and $B V$ phenotypes in some experiments, with the result that $B V$ phenotypes may be included in class $b v$; (2) poorer viability of classes homozygous for vestigial, namely, $B v$ and $b v$. Making allowance for these disturbing factors, it is quite possible that the correct percentage will be 50 .

I am satisfied, therefore, that the stock I have used and which was labelled "black" may have been "sooty", so that the results must of necessity show independent segregation.

I regret the misleading results arrived at due to erroneous labelling of the stock, and I wish to thank Mr. Moriwaki for his comment.

Department of Zoology,

G. Eloff.

University of the Witwatersrand, Johannesburg.

April 22.

\section{Suggested Cases for Suspension of Rules of Nomenclature}

Attention of the zoological profession is invited to the fact that request for the "Suspension of the Rules" has been made in the following cases, on the ground that "the strict application of the Règles will clearly result in greater confusion than uniformity". 